\title{
Hypertensive retinopathy and associated factors among nondiabetic chronic kidney disease patients seen at a tertiary hospital in Tanzania: a cross-sectional study
}

This article was published in the following Dove Press journal:

International Journal of Nephrology and Renovascular Disease

Pilly Chillo'

Ame Ismail'

Anna Sanyiwa ${ }^{2}$

Paschal Ruggajo'

Appolinary Kamuhabwa ${ }^{3}$

'Department of Internal Medicine, Muhimbili University of Health and Allied

Sciences, Dar es Salaam, Tanzania;

${ }^{2}$ Department of Ophthalmology,

Muhimbili University of Health and Allied

Sciences, Dar es Salaam, Tanzania;

${ }^{3}$ Department of Clinical Pharmacy and Pharmacology, Muhimbili University of Health and Allied Sciences, Dar es

Salaam, Tanzania
Correspondence: Pilly Chillo

Department of Internal Medicine,

Muhimbili University of Health and Allied

Sciences, PO Box 6500I, Dar es Salaam,

Tanzania

Tel +255222150603

Fax +255 22 2150465

Email pchillo2000@yahoo.co.uk
Background: Hypertensive retinopathy is a known marker of cardiovascular disease, and among unselected patients with chronic kidney disease (CKD) more severe retinopathy has been associated with lower estimated glomerular filtration rate (eGFR). This association has, however, not been widely studied among nondiabetic hypertensive patients with CKD, especially in sub-Saharan Africa. We aimed to determine the prevalence and severity of hypertensive retinopathy and its relationship with eGFR among nondiabetic CKD patients seen at Muhimbili National Hospital in Dar es Salaam, Tanzania.

Methods: A hospital-based cross-sectional study was conducted among nondiabetic CKD adult ( $\geq 18$ years) patients with hypertension. A structured questionnaire was used to record patients' demographic characteristics and their cardiovascular risk profile. eGFR was calculated using the Modification of Diet in the Renal Disease (MDRD) equation and only patients with CKD stage 3 or more were enrolled in the study. Grading of retinopathy was done using the Keith-Wagener classification.

Results: In total, 224 patients fulfilled the inclusion criteria and were enrolled. Their mean age was $45.8 \pm 14.1$ years, and $59.4 \%$ were men. The proportions of patients with stage 3,4 , and 5 CKD were $21.4 \%, 19.6 \%$, and $58.9 \%$, respectively. Hypertensive retinopathy was present in $157(70.1 \%)$ patients and the proportions with grade I, grade II, grade III, and grade IV retinopathy were $17.9 \%, 18.8 \%, 19.6 \%$, and $13.8 \%$, respectively. The severity of retinopathy increased with decreasing levels of eGFR, and in multivariate logistic regression analysis, factors found to be independently associated with $\geq$ grade II hypertensive retinopathy were more severe CKD, higher hypertension grades, and alcohol use, all $p<0.05$.

Conclusion: The prevalence of hypertensive retinopathy is high among nondiabetic CKD patients seen at a tertiary hospital in Tanzania and is independently associated with CKD severity. Retinopathy grade can be used as a marker of CKD severity among these patients. Keywords: sub-Saharan Africa, cardiovascular disease, renovascular disease, cardiovascular markers

\section{Introduction}

The presence of hypertensive retinopathy signifies widespread systemic vascular damage due to hypertension, ${ }^{1}$ and both the prevalence and severity of retinopathy increase when hypertension and diabetes coexist. ${ }^{2}$ Hence, the retinal microcirculation accessible through direct noninvasive visualization offers a great opportunity to 
explore the association of systemic microvascular disease caused by hypertension and its relationship with cardiovascular diseases, including chronic kidney disease (CKD). Previous studies from unselected CKD cohorts have reported associations between more severe retinopathy and worse CKD levels, especially among diabetic patients. $^{3-5}$ In the large Chronic Renal Insufficiency Cohort (CRIC) study, the prevalence of retinopathy was $49 \%$ among CKD patients with diabetes as opposed to $11 \%$ in those without diabetes, with lower levels of eGFR independently predicting retinopathy severity among diabetic patients but not among hypertensive patients in that study. ${ }^{3}$

In sub-Saharan Africa, the prevalence of CKD has significantly increased in the past decades and is mainly caused by hypertension, ${ }^{6}$ as opposed to developed countries where diabetes is the main culprit. ${ }^{7}$ Moreover, CKD in sub-Saharan Africa affects younger people and often presents with severe disease and early mortality. ${ }^{6}$ It has been suggested from previous studies in America and Asia that the presence of retinopathy in CKD patients may provide additional information of prognostic value regarding renal diseases progression ${ }^{3,5}$ as well as incident cardiovascular events including mortality from cardiovascular disease. ${ }^{89}$ In Africa, majority of previous studies have reported on the prevalence of retinopathy among general hypertensive patients, ${ }^{10-12}$ while only one study reported on the prevalence of retinopathy among CKD patients, ${ }^{13}$ and it is not known whether retinopathy severity can be used as a marker of CKD severity among native subSaharan CKD patients, especially when diabetes does not coexist with hypertension. Furthermore, it is not known how other factors such as alcohol consumption, cigarette smoking, age, and gender of the patient affect retinopathy severity among native sub-Saharan CKD patients. The present study was designed to address this gap.

\section{Material and methods Study design and data collection}

This was a hospital-based descriptive cross-sectional study conducted at the Nephrology Clinic of Muhimbili National Hospital which is the topmost referral hospital in Tanzania. Patients were consecutively recruited into the study as they attended the clinic. We included all adult ( $\geq 18$ years) patients with stage 3 or more CKD, who were also hypertensive. Patients known to have diabetes mellitus and those on dialysis were excluded. The study took place between September 2015 and April 2016. Based on previous studies, a sample size of 220 was enough to estimate the prevalence of retinopathy in this cohort, with a margin error of $5 \%$ at $95 \%$ CI.

A structured questionnaire was used to obtain demographic characteristics and record history of cardiovascular risk factors, including history of alcohol consumption and cigarette smoking. Patients were defined as using alcohol if they indicated that they regularly consume alcohol, while a positive history of cigarette smoking was defined as both current and past smoking. Height was measured using a stadiometer (Seca $\AA$, USA), with subjects wearing no shoes and averaged to the nearest centimeter. Weight was measured by a weighing scale (Momert ${ }^{\circledR}$, China) and recorded in kilogram. Height and weight measurements were used to calculate body mass index (BMI) as follows: $\mathrm{BMI}=$ weight in $\mathrm{kg}$ /height in $\mathrm{m}^{2}$. Obesity was defined as BMI $\geq 30 \mathrm{~kg} / \mathrm{m}^{2}$. Blood pressure (BP) was taken using a mercury sphygmomanometer. This was done in a quiet room after a 5 mins' rest. A total of three readings were taken, and the average of the last two readings was taken as the patient's BP. Hypertension was defined as BP $\geq 140 / 90 \mathrm{mmHg}$, or use of antihypertensive medications, and was categorized as grade I (140-159/90-99 $\mathrm{mmHg})$, grade II (160-179/100-109 mmHg), and grade III $(\geq 180 / \geq 110 \mathrm{mmHg})$ according to European Society of Cardiology guidelines. ${ }^{14}$

\section{CKD and retinopathy grading}

Blood was taken and analyzed for serum creatinine. Serum creatinine levels were used to calculate the estimated glomerular filtration rate (eGFR), using the Modification of Diet in the Renal Disease (MDRD) equation ${ }^{15}$ as follows: eGFR $\left(\mathrm{mL} / \mathrm{min} / 1.73 \mathrm{~m}^{2}\right)=175 \times(\mathrm{Scr} / 88.4)^{-1.154} \times$ $(\text { Age })^{-0.203} \times 0.742$ (if female) $\times 1.212$ (for Africans) Only patients with eGFR of $<60 \mathrm{ml} / \mathrm{min} / 1.73 \mathrm{~m}^{2}$ were included in this study. CKD was staged as stage 3 , stage 4 , and stage 5 according to guidelines. ${ }^{16}$

All study participants were sent to the eye clinic for standard ophthalmology evaluation. Visual acuity (VA) of the patient was evaluated before dilatation of the pupil. Full examination including pupil reflexes, anterior segment, and posterior segment, was done. Fundus examination was done using slit-lamp indirect ophthalmoscopy with noncontact slit-lamp lenses (90D double aspheric Volk lens; Shanghai, China). Patients found to have hypertensive retinopathy by ophthalmoscopy were subjected to fundus photography. The presence of the following was noted and used to grade the retinopathy; microaneurysms, retinal hemorrhages, cotton wool spots, exudates, arteriovenous nipping, arteriolar 
narrowing, and papilloedema. All study patients were reviewed by a medical retina specialist for verification and grading. Grading of the retinopathy was done using the Keith-Wagener classification ${ }^{17}$ as shown below:

* Grade I - mild generalized retinal arteriolar narrowing or sclerosis

* Grade II - definate focal narrowing and arteriovenous crossings. Moderate-to-marked sclerosis of the retinal arterioles. Exaggerated arterial light reflex

* Grade III - retinal hemorrhages, exudates, and cotton wool spots. Sclerosis and spastic lesions of retinal arterioles

* Grade IV - severe grade III and papilledema.

\section{Data handling and ethical issues}

Data entry and analysis was done using SPSS version 20. Data are presented as mean \pm SD for continuous variables and as percentages for categorical variables. Groups of patients were compared using $\chi^{2}$ test, unpaired Student's $t$-test, or one-way ANOVA as appropriate. Multivariate logistic regression analysis was performed to identify independent variables associated with hypertensive retinopathy in nondiabetic patients with CKD. A $p$-value of $<0.05$ was considered to indicate a statistical significant difference.

The study was done in accordance with the Helsinki declaration of studies on human subjects. Ethical clearance was obtained from the Directorate of Research and Publication of Muhimbili University of Health and Allied Sciences. All patients signed an informed consent form before enrollment into the study.

\section{Results}

A total of 305 patients were screened to take part in the study, but only 224 were found to be eligible, constituting the present study population. Reasons for ineligibility were as follows: 2 patients were younger than 18 years, 9 patients were not hypertensive, 9 patients' creatinine levels could not be traced from the laboratory, and 6 patients did not turn up for ophthalmology examination. Furthermore, we excluded all 55 CKD patients who were on dialysis because their predialysis serum creatinine levels were not available at the time of the study.

The mean age of the study population was $45.8 \pm 14.3$ years (range $18-90$ years), and 133 (59.4\%) were men. Most of the patients had primary education as their highest level of education and $72.3 \%$ were unemployed. About one-third (35.7\%) of the patients were using alcohol and $21 \%$ had ever smoked. Table 1 summarizes the sociodemographic characteristics of the study population.

The mean systolic BP of the total population was $144 \pm 27$ $\mathrm{mmHg}$ and was not different between men $(143 \pm 27 \mathrm{mmHg})$ and women $(145 \pm 28 \mathrm{mmHg}), p=0.544$. At the time of enrollment, the proportion of CKD patients with controlled (normal), Grade I, Grade II, and Grade III hypertension was $46.4 \%, 19.6 \%, 14.7 \%$, and $19.2 \%$, respectively. The mean BMI of the total studied was $23.4 \pm 3.3 \mathrm{~kg} / \mathrm{m}^{2}$, and only 6 (2.7\%) patients were found to be obese. The mean anthropometric, BP, serum creatinine, and eGFR levels of the study population are summarized in Table 2.

One hundred and eighty-seven patients (58.9\%) had stage 5 (end-stage renal disease) CKD, while 44 (19.6\%) had stage 4

Table I Demographic characteristics of the study population $(\mathrm{N}=224)$

\begin{tabular}{|l|l|l|}
\hline Characteristic & Frequency & Percentage (\%) \\
\hline Sex & & \\
Male & 133 & 59.4 \\
Female & 91 & 40.6 \\
\hline Age groups (years) & & \\
I8-35 & 50 & 22.3 \\
$36-45$ & 67 & 29.9 \\
$46-55$ & 60 & 26.8 \\
$56-65$ & 25 & 11.2 \\
$>65$ & 22 & 9.8 \\
\hline Level of education & & \\
No formal education & 11 & 4.9 \\
Primary & 124 & 55.4 \\
Secondary & 66 & 29.5 \\
College and above & 23 & 10.3 \\
\hline Marital status & & \\
Single & 28 & 12.5 \\
Married/cohabiting & 186 & 83.0 \\
Divorced/widowed & 10 & 4.5 \\
\hline Employment status & & 23.7 \\
Employed & 53 & 39.0 \\
Unemployed & 162 & 35.7 \\
Retired & 9 & \\
\hline Alcohol consumption & & \\
Yes & 80 & \\
No & 144 & \\
\hline Smoking & & \\
Yes & No & \\
\hline
\end{tabular}


Table 2 Levels of blood pressure, anthropometric measurements, and creatinine in the study population

\begin{tabular}{|l|l|l|}
\hline Measurement & Mean \pm SD & Range \\
\hline Systolic blood pressure $(\mathrm{mmHg})$ & $144 \pm 27$ & $87-240$ \\
Diastolic blood pressure $(\mathrm{mmHg})$ & $87 \pm 15$ & $60-141$ \\
Height $(\mathrm{cm})$ & $164 \pm 8$ & $145-187$ \\
Weight $(\mathrm{kg})$ & $63 \pm 10$ & $36-90$ \\
BMI $\left(\mathrm{kg} / \mathrm{m}^{2}\right)$ & $23.4 \pm 3.3$ & $15.9-33.1$ \\
Serum ceatinine $(\mu \mathrm{mol} / \mathrm{L})$ & $770 \pm 680$ & $115-3,27 \mid$ \\
Estimated GFR $\left(\mathrm{mL} / \mathrm{min} / \mathrm{l} .73 \mathrm{~m}^{2}\right)$ & $16.7 \pm 14.5$ & $1.5-57.9$ \\
\hline
\end{tabular}

Abbreviations: BMI, body mass index; GFR, glomerular filtration rate.

and $48(21.4 \%)$ were in stage 3 . On the other hand, hypertensive retinopathy was present in $157(70.1 \%)$ patients in the total population. The proportion of patients with Grade I, Grade II, Grade III, and Grade IV retinopathy was 17.9\%, 18.8\%, $19.6 \%$, and $13.8 \%$, respectively. The most common antihypertensive and/or heart failure medications used were diuretics, calcium channel blockers, and hydralazine (Figure 1).

Both mean systolic and diastolic BP levels showed an increasing trend with increasing levels of retinopathy severity. Similarly, the mean creatinine level increased with increasing retinopathy severity, while the mean eGFR decreased with increasing retinopathy severity. Age and BMI did not show significant trends with increasing retinopathy severity, Table 3 .
The proportion of patients with stage 5 CKD (endstage renal disease) increased with increasing severity of retinopathy grade, while the proportion of patients with stage 3 CKD (mild CKD) decreased with increasing severity of retinopathy grading, $p<0.001$ (Figure 2).

CKD patients with retinopathy were more likely to take alcohol and had higher systolic and diastolic BP, higher serum creatinine levels, and lower levels of eGFR when compared to CKD patients without retinopathy, all $p<0.05$ (Table 4). They, however, did not differ in terms of age, gender, smoking status, and mean BMI levels (Table 4).

Predictors of grade II or more hypertensive retinopathy among CKD patients were identified using logistic regression analysis in a model that included CKD stage, hypertension grade, alcohol intake, age, and gender of the patients (Table 5). The independent predictors of having $\geq$ grade II hypertensive retinopathy among nondiabetic CKD patients were more severe CKD levels, higher BP levels, and use of alcohol, irrespective of age and gender of the patient, Table 5.

\section{Discussion}

The present study was done to determine the prevalence and associated factors of hypertensive retinopathy among nondiabetic CKD patients as seen at a tertiary health facility in Tanzania. We found the prevalence of

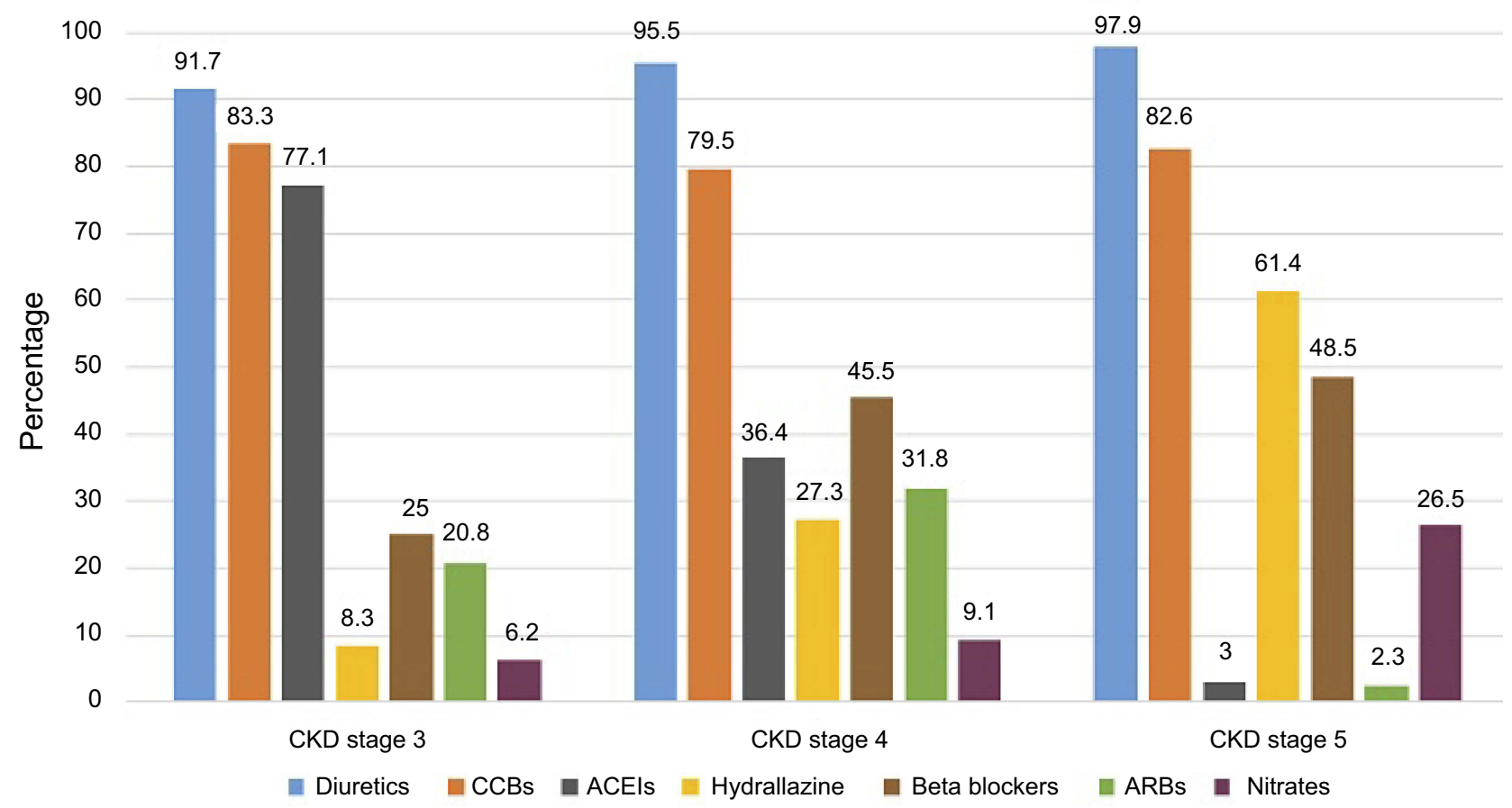

Figure I Medications used in relation to CKD stage.

Abbreviations: $C C B$, calcium channel blockers; ACEls, angiotensin-converting enzyme inhibitors; ARBs, angiotensin receptor blockers; CKD, chronic kidney disease. 
Table 3 Association between age, blood pressure, body mass index, and serum creatinine levels with retinopathy severity in the total population

\begin{tabular}{|c|c|c|c|c|c|c|}
\hline Characteristics & $\begin{array}{l}\text { No retino- } \\
\text { pathy } \\
n=67\end{array}$ & $\begin{array}{l}\text { Grade } \\
\text { I retinopathy } \\
n=40\end{array}$ & $\begin{array}{l}\text { Grade II reti- } \\
\text { nopathy } \\
n=42\end{array}$ & $\begin{array}{l}\text { Grade III reti- } \\
\text { nopathy } \\
n=44\end{array}$ & $\begin{array}{l}\text { Grade IV reti- } \\
\text { nopathy } \\
n=3 \text { I }\end{array}$ & $p$-value \\
\hline Age (years) & $48 \pm 15$ & $44 \pm 15$ & $47 \pm 12$ & $47 \pm 12$ & $4 I \pm 15$ & 0.127 \\
\hline $\mathrm{SBP}(\mathrm{mmHg})$ & $135 \pm 20$ & $136 \pm 26$ & $139 \pm 24$ & $153 \pm 29$ & $164 \pm 29$ & $<0.001$ \\
\hline $\mathrm{DBP}(\mathrm{mmHg})$ & $83 \pm 13$ & $87 \pm 15$ & $85 \pm 13$ & $93 \pm 18$ & $103 \pm 21$ & $<0.001$ \\
\hline BMI $\left(\mathrm{kg} / \mathrm{m}^{2}\right)$ & $22.9 \pm 3.4$ & $23.4 \pm 3.4$ & $23.4 \pm 3.0$ & $24.5 \pm 3.6$ & $23.2 \pm 3.1$ & 0.252 \\
\hline Serum creatinine $(\mu \mathrm{mol} / \mathrm{l})$ & $468 \pm 462$ & $692 \pm 711$ & $696 \pm 666$ & $|| 36 \pm 77 \mid$, & $\mathrm{I}, 103 \pm 568$ & $<0.001$ \\
\hline $\begin{array}{l}\text { Estimated GFR }(\mathrm{mL} / \mathrm{min} / \\
\left.1.73 \mathrm{~m}^{2}\right)\end{array}$ & $24 \pm 15$ & $21 \pm 17$ & $16 \pm 12$ & $9 \pm 9$ & $7 \pm 5$ & $<0.001$ \\
\hline
\end{tabular}

Note: Results are mean \pm SD.

Abbreviations: SBP, systolic blood pressure; DBP, diastolic blood pressure; BMI, body mass index; GFR, glomerular filtration rate.

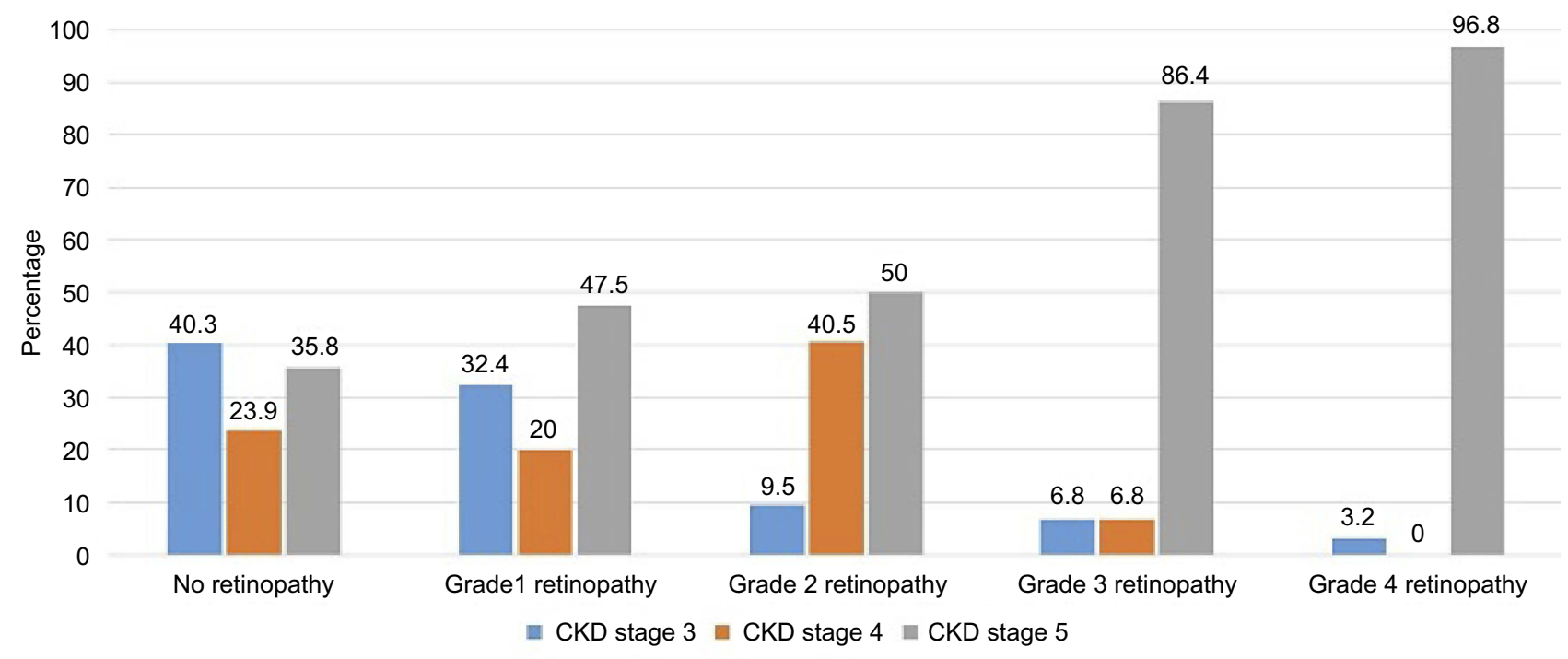

Figure 2 Proportion of patients with stage 3, stage 4, and stage 5 CKD in groups of retinopathy severity. Abbreviation: CKD, chronic kidney disease.

hypertensive retinopathy to be high in this group of patients $(70.1 \%)$, and that the severity of retinopathy increased with increasing severity of CKD. Furthermore, more severe $\mathrm{CKD}$, higher hypertension grades, as well as alcohol consumption, independently predicted the presence of more than mild hypertensive retinopathy in these patients.

The prevalence of hypertensive retinopathy of $70.1 \%$ found in this study is much higher than that found in large studies of CKD patients in the United States of America. ${ }^{3,4}$ Both the Chronic Renal Insufficiency Cohort (CRIC) study and the Atherosclerosis Risk in Communities (ARIC) studies were population studies that enrolled people in the communities who most likely had mild forms of CKD and hence lower prevalences of retinopathy as compared to our study which enrolled hospital patients. Our prevalence of retinopathy among CKD patients is, however, similar to that by Deva et al (67\%) among 150 hospital patients with CKD stages 3-5 in Australia. ${ }^{18}$ Furthermore, in another study by Kabedi et al that looked on hypertensive retinopathy and associated factors in Kinshasa, 25 of the 28 CKD patients in that study had retinopathy, giving a prevalence of $89 \% .^{13}$ Both the study by Deva et al and Kabedi et al were hospital based and therefore likely to have CKD patients with advanced disease and therefore with similar high prevalences of retinopathy as found in the present study. 
Table 4 Characteristics of patients with and without retinopathy

\begin{tabular}{|l|l|l|l|}
\hline $\begin{array}{l}\text { Characteri- } \\
\text { stic }\end{array}$ & $\begin{array}{c}\text { No retino- } \\
\text { pathy } \\
(\mathbf{n = 6 7 )}\end{array}$ & $\begin{array}{c}\text { Retinopathy } \\
\text { present } \\
(\mathbf{n}=157)\end{array}$ & $p$-value \\
\hline Age (years) & $47.7 \pm 15.3$ & $44.9 \pm 13.6$ & 0.184 \\
Men n (\%) & $37(55.2)$ & $96(61.1)$ & 0.409 \\
Smoking n (\%) & $11(16.4)$ & $36(22.9)$ & 0.273 \\
Alcohol n (\%) & $15(22.4)$ & $65(41.4)$ & 0.007 \\
BMI $\left(\mathrm{kg} / \mathrm{m}^{2}\right)$ & $22.9 \pm 3.4$ & $23.6 \pm 3.3$ & 0.183 \\
SBP $(\mathrm{mmHg})$ & $135 \pm 20$ & $147 \pm 29$ & 0.002 \\
DBP $(\mathrm{mmHg})$ & $83 \pm 13$ & $91 \pm 18$ & 0.001 \\
Creatinine & $468 \pm 462$ & $899 \pm 718$ & $<0.001$ \\
$(\mu \mathrm{mol} / \mathrm{L})$ & & & $<0.001$ \\
eGFR $(\mathrm{mL} / \mathrm{min} /$ & $24 \pm 15$ & $13.6 \pm 13.0$ & \\
I.73 $\left.\mathrm{m}^{2}\right)$ & & & \\
\hline
\end{tabular}

Note: Results are mean \pm SD unless stated otherwise.

Abbreviations: BMI, body mass index; SBP, systolic blood pressure; DBP, diastolic blood pressure; eGFR, estimated glomerular filtration rate.

Table 5 Predictors of $\geq$ grade II hypertensive retinopathy among CKD patients identified in logistic regression analysis

\begin{tabular}{|l|l|l|l|}
\hline Variable & OR & $\mathbf{9 5 \%} \mathbf{~ C l ~}$ & p-value \\
\hline CKD stage & & & \\
Stage 3 & Reference & & \\
Stage 4 & 4.28 & $1.56-I I .74$ & 0.005 \\
Stage 5 & 8.62 & $3.56-20.87$ & $<0.00 \mathrm{I}$ \\
Hypertension grade & & & \\
Normal (controlled) & Reference & & \\
Grade I & 2.67 & $1.18-6.05$ & 0.018 \\
Grade II & 2.35 & $0.97-5.7 I$ & 0.059 \\
Grade III & $2.5 \mathrm{I}$ & $1.09-5.80$ & 0.031 \\
Alcohol intake & & & \\
No & Reference & & \\
Yes & 2.08 & $1.09-3.97$ & 0.026 \\
Female sex & 0.93 & $0.49-1.76$ & 0.814 \\
Age >55 years & 0.99 & $0.97-1.02$ & 0.605 \\
\hline
\end{tabular}

We found the severity of CKD to increase as the severity of retinopathy increased. Of note, the mean eGFR level decreased from $24 \mathrm{~mL} / \mathrm{min} / 1.73 \mathrm{~m}^{2}$ in CKD patients without retinopathy to $7 \mathrm{~mL} / \mathrm{min} / 1.73 \mathrm{~m}^{2}$ in those with stage 4 retinopathy. Similarly, the proportion of stage 5 CKD patients was found to be $35.8 \%$ in CKD patients without retinopathy and increased to $96.8 \%$ in those with stage 4 retinopathy. Last, CKD patients with stage 4 and stage 5 were, respectively, 4 and 8 times more likely to have more than mild hypertensive retinopathy when compared to those with stage $3 \mathrm{CKD}$. These findings are in agreement with many previous studies in literature ${ }^{3,4,13,18-20}$ and confirm the general observation that retinal microvascular abnormalities are associated with renal dysfunction and the suggestion that common systemic microvascular processes may underlie the development of microvascular damage in the eye and kidneys. ${ }^{21}$ More interestingly, the presence of more severe CKD predicted more than mild retinopathy independent of other risk factors including hypertension, suggesting that severity of retinopathy provides additional information on the severity of CKD. Retinal pathologic features are associated with inflammatory processes ${ }^{22,23}$ and endothelial dysfunction, leading to circulatory abnormalities and reduced vascular reactivity. ${ }^{24}$ Both retinopathy and nephropathy involve thickening of the basement membrane and muscular layers and increased leakage. ${ }^{21}$ These pathologic and hemodynamic abnormalities may occur throughout the body and their effects on the retinal vasculature may be useful indicators of cumulative microvascular damage from hypertension, inflammation, and other processes. ${ }^{23}$

The finding that hypertension severity predicted the presence of retinopathy is similar to previous studies in the literature. ${ }^{25}$ Hypertension is a known traditional risk factor for microvascular damage and plays a pivotal role in the pathogenesis of both CKD and retinopathy. ${ }^{25}$ Much of the contribution to retinopathy among CKD patients in Western cohorts is known to be from diabetes mellitus. ${ }^{3,23}$ In the CRIC study, for example, CKD patients with hypertension alone had a prevalence of retinopathy of $9 \%$, while CKD patients with diabetes alone had $39.5 \%$ and the combination of diabetes and hypertension made the prevalence of retinopathy to rise to $45.3 \% .^{3}$ In sub-Saharan Africa, hypertension has been considered the main culprit of $\mathrm{CKD},{ }^{6}$ and the present findings add to literature that hypertension severity is independently associated with retinopathy among nondiabetic CKD patients irrespective of other traditional risk factors. Moreover, because hypertension is the main cause of CKD in this part of the world, the findings in this study truly represent the main CKD population in sub-Saharan Africa - the one that is predominantly hypertensive as opposed to Western CKD cohorts, whose underlying pathology is mainly diabetes. ${ }^{7}$

Our finding that alcohol consumption was independently associated with retinopathy is an interesting one. Both the $\mathrm{CRIC}^{3}$ and $\mathrm{ARIC}^{4}$ studies did not include alcohol as a risk factor for retinopathy in CKD patients. The study by Kabedi et al in Kinshasa included history of alcohol consumption in 
the multivariable analysis, but no independent association with retinopathy was found. ${ }^{13}$ Alcohol consumption was associated with increased risk of VA in a large cohort of type 2 diabetic patients participating in the ADVANCE (Action in Diabetes and Vascular Disease: Pretax and Diamicron MR Controlled Evaluation) trial, but not with retinopathy. $^{26}$ Furthermore, there are still contradictory results in literature regarding the association between alcohol use and retinopathy, with some studies reporting positive $\mathrm{e}^{27,28}$ while others inverse associations, ${ }^{29}$ as well as suggestion of a U-shaped curve relationship ie moderate drinkers being at a lower risk compared with heavy drinkers or abstainers. ${ }^{30}$ The mechanisms of the influence of alcohol consumption on the risk of retinopathy are not clear but might operate through the intermediary of alcohol-induced hypertension. ${ }^{31}$ Our findings, therefore, call for more studies to look in detail the association of alcohol consumption in terms of amount, type, and duration in relation to retinopathy among native sub-Saharan African populations.

We found in this study many demographic similarities with previous studies on CKD patients in the sub-Saharan African region. The mean age of 46 years found in this study is similar to previous studies in the region, ${ }^{32-34}$ and the present findings add to the observation that subSaharan patients with CKD are younger when compared to those in the developed countries. ${ }^{3,4,35}$ Furthermore, there was a slight male predominance, a finding that is also similar to previous studies in the region. ${ }^{34,36}$

The strengths of this study include its patients' selection whereby only hypertensive patients were studied; therefore, the retinopathy seen among these patients may be regarded as truly hypertensive in nature, as opposed to a mixed diabetic hypertensive retinopathy picture when unselected CKD patients are studied. One of the limitations of the study is its cross-sectional nature which does not allow inference of causality, and it is possible that retinopathy occurred before CKD and vice versa. We did not include patients on dialysis because pre-dialysis serum creatinine was not available and serum creatinine levels after dialysis could not be used as a measure of CKD severity at the time of data collection.

\section{Conclusion}

Hypertensive retinopathy is found in $70.1 \%$ of nondiabetic CKD patients attending the Nephrology Unit at Muhimbili National Hospital. CKD severity, hypertension severity, and use of alcohol are independently associated with retinopathy in these patients.

\section{Acknowledgments}

We thank the Muhimbili University of Health and Allied Sciences for supporting this study.

\section{Disclosure}

The authors report no conflicts of interest in this work.

\section{References}

1. Bhargava M, Ikram MK, Wong TY. How does hypertension affect your eyes? J Hum Hypertens. 2012;26(2):71-83. doi:10.1038/ jhh.2011.37

2. Long AN, Dagogo-Jack S. Comorbidities of diabetes and hypertension: mechanisms and approach to target organ protection. $J$ Clin Hypertens (Greenwich). 2011;13(4):244-251. doi:10.1111/j.17517176.2011.00434.x

3. Grunwald JE, Alexander J, Ying GS, et al. Retinopathy and chronic kidney disease in the Chronic Renal Insufficiency Cohort (CRIC) study. Arch Ophthalmol. 2012;130(9):1136-1144. doi:10.1001/ archophthalmol.2012.1800

4. Wong TY, Coresh J, Klein R, et al. Retinal microvascular abnormalities and renal dysfunction: the atherosclerosis risk in communities study. J Am Soc Nephrol. 2004;15(9):2469-2476. doi:10.1097/01. ASN.0000136133.28194.E4

5. Sabanayagam C, Shankar A, Koh D, et al. Retinal microvascular caliber and chronic kidney disease in an Asian population. Am $J$ Epidemiol. 2009;169(5):625-632. doi:10.1093/aje/kwn367

6. Naicker S. Burden of end-stage renal disease in sub-Saharan Africa. Clin Nephrol. 2010;74(Suppl 1):S13-S16.

7. Neuen BL, Chadban SJ, Demaio AR, Johnson DW, Perkovic V. Chronic kidney disease and the global NCDs agenda. BMJ Glob Health. 2017;2(2):e000380. doi:10.1136/bmjgh-2017-000306

8. Hwang HS, Kim SY, Hong YA, et al. Clinical impact of coexisting retinopathy and vascular calcification on chronic kidney disease progression and cardiovascular events. Nutr Metab Cardiovasc Dis. 2016;26(7):590-596. doi:10.1016/j.numecd.2016.02.005

9. Ricardo AC, Grunwald JE, Parvathaneni S, Goodin S, Ching A, Lash JP. Retinopathy and CKD as predictors of all-cause and cardiovascular mortality: National Health and Nutrition Examination Survey (NHANES) 1988-1994. Am J Kidney Dis. 2014;64 (2):198-203. doi:10.1053/j.ajkd.2014.01.437

10. Geletu AH, Teferra AS, Sisay MM, Teshome DF. Incidence and predictors of chronic kidney diseases among type 2 diabetes mellitus patients at St. Paul's Hospital, Addis Ababa, Ethiopia. BMC Res Notes. 2018;11(1):532. doi:10.1186/s13104-018-3618-9

11. Nwankwo EA, Wudiri WW, Akinsola A. Risk factors for the development of Chronic Kidney Disease among Nigerians with essential hypertension. J Med Sci. 2017;7(4):579-584.

12. Omotoso AB, Kolo PM, Olanrewaju TO, Owoeye JF, Biliaminu SA, Olatunji VA. Relationship between retinopathy and renal abnormalities in black hypertensive patients. Clin Hypertens. 2016;22:19. doi:10.1186/s40885-016-0053-x

13. Kabedi NN, Mwanza JC, Lepira FB, Kayembe TK, Kayembe DL. Hypertensive retinopathy and its association with cardiovascular, renal and cerebrovascular morbidity in Congolese patients. Cardiovasc J Afr. 2014;25(5):228-232. doi:10.5830/CVJA-2014-045

14. Mancia G, De Backer G, Dominiczak A, et al. 2007 guidelines for the management of arterial hypertension: the task force for the management of arterial hypertension of the European Society of Hypertension (ESH) and of the European Society of Cardiology (ESC). J Hypertens. 2007;25(6):1105-1187. doi:10.1097/HJH.0 b013e3281fc 975 a 
15. Levey AS, Bosch JP, Lewis JB, Greene T, Rogers N, Roth D. A more accurate method to estimate glomerular filtration rate from serum creatinine: a new prediction equation. Modification of Diet in Renal Disease Study Group. Ann Intern Med. 1999;130(6):461-470.

16. Group KW. KDIGO 2012 clinical practice guideline for the evaluation and management of chronic kidney disease. Kidney Int. 2013;3(1):1-150.

17. Keith NM, Wagener HP, Barker NW. Some different types of essential hypertension: their course and prognosis. Am J Med Sci. 1974;268(6):336-345.

18. Deva R, Alias MA, Colville D, et al. Vision-threatening retinal abnormalities in chronic kidney disease stages 3 to 5. Clin $\mathrm{J} \mathrm{Am}$ Soc Nephrol. 2011;6(8):1866-1871. doi:10.2215/CJN.10321110

19. Gao B, Zhu L, Pan Y, Yang S, Zhang L, Wang H. Ocular fundus pathology and chronic kidney disease in a Chinese population. BMC Nephrol. 2011;12:62. doi:10.1186/1471-2369-12-62

20. Ng WY, Teo BW, Tai ES, et al. Cystatin C, chronic kidney disease and retinopathy in adults without diabetes. Eur J Prev Cardiol. 2016;23(13):1413-1420. doi:10.1177/2047487316637182

21. Blum M, Saemann A, Wolf G. The eye, the kidney and microcirculation. Nephrol Dial Transplant. 2011;26(1):4-6. doi:10.1093/ndt/gfq425

22. Klein BE, Knudtson MD, Tsai MY, Klein R. The relation of markers of inflammation and endothelial dysfunction to the prevalence and progression of diabetic retinopathy: wisconsin epidemiologic study of diabetic retinopathy. Arch Ophthalmol. 2009;127(9):1175-1182. doi:10.1001/archophthalmol.2009.172

23. Wong TY, Islam FM, Klein R, et al. Retinal vascular caliber, cardiovascular risk factors, and inflammation: the multi-ethnic study of atherosclerosis (MESA). Invest Ophthalmol Vis Sci. 2006;47 (6):2341-2350. doi:10.1167/iovs.05-1539

24. Robinson F, Riva CE, Grunwald JE, Petrig BL, Sinclair SH. Retinal blood flow autoregulation in response to an acute increase in blood pressure. Invest Ophthalmol Vis Sci. 1986;27(5):722-726.

25. Wong TY, McIntosh R. Hypertensive retinopathy signs as risk indicators of cardiovascular morbidity and mortality. $\mathrm{Br}$ Med Bull. 2005;73-74:57-70. doi:10.1093/bmb/ldh050

26. Lee CC, Stolk RP, Adler AI, et al. Association between alcohol consumption and diabetic retinopathy and visual acuity-the AdRem Study. Diabet Med. 2010;27(10):1130-1137. doi:10.1111/j.1464-5491.2010.03080.x
27. Young RJ, McCulloch DK, Prescott RJ, Clarke BF. Alcohol: another risk factor for diabetic retinopathy? $\mathrm{Br}$ Med $J$. 1984;288 (6423):1035-1037.

28. Martin-Merino E, Fortuny J, Rivero-Ferrer E, Lind M, GarciaRodriguez LA. Risk factors for diabetic retinopathy in people with Type 2 diabetes: a case-control study in a UK primary care setting. Prim Care Diabetes. 2016;10(4):300-308. doi:10.1016/j. pcd.2016.01.002

29. Fenwick EK, Xie J, Man RE, et al. Moderate consumption of white and fortified wine is associated with reduced odds of diabetic retinopathy. $J$ Diabetes Complications. 2015;29(8):1009-1014. doi:10.1016/j.jdiacomp.2015.09.001

30. Beulens JW, Kruidhof JS, Grobbee DE, Chaturvedi N, Fuller JH, Soedamah-Muthu SS. Alcohol consumption and risk of microvascular complications in type 1 diabetes patients: the EURODIAB Prospective Complications Study. Diabetologia. 2008;51 (9):1631-1638. doi:10.1007/s00125-008-1091-z

31. Husain K, Ansari RA, Ferder L. Alcohol-induced hypertension: mechanism and prevention. World J Cardiol. 2014;6(5):245-252. doi:10.4330/wjc.v6.i5.245

32. Babua C, Kalyesubula R, Okello E, et al. Cardiovascular risk factors among patients with chronic kidney disease attending a tertiary hospital in Uganda. Cardiovasc J Afr. 2015;26(4):177-180. doi:10.5830/ CVJA-2015-045

33. Ulasi II, Arodiwe EB, Ijoma CK. Left ventricular hypertrophy in African Black patients with chronic renal failure at first evaluation. Ethn Dis. 2006;16(4):859-864.

34. Halle MP, Takongue C, Kengne AP, Kaze FF, Ngu KB. Epidemiological profile of patients with end stage renal disease in a referral hospital in Cameroon. BMC Nephrol. 2015;16:59. doi:10.1186/s12882-015-0044-2

35. Go AS, Chertow GM, Fan D, McCulloch CE, Hsu CY. Chronic kidney disease and the risks of death, cardiovascular events, and hospitalization. $N$ Engl $J$ Med. 2004;351(13):1296-1305. doi:10.1056/NEJMoa041031

36. Arogundade FA, Sanusi AA, Hassan MO, Akinsola A. The pattern, clinical characteristics and outcome of ESRD in Ile-Ife, Nigeria: is there a change in trend? Afr Health Sci. 2011;11 (4):594-601.

\section{Publish your work in this journal}

The International Journal of Nephrology and Renovascular Disease is an international, peer-reviewed open-access journal focusing on the pathophysiology of the kidney and vascular supply. Epidemiology, screening, diagnosis, and treatment interventions are covered as well as basic science, biochemical and immunological studies. The manuscript management system is completely online and includes a very quick and fair peer-review system, which is all easy to use. Visit http://www.dovepress.com/testimonials.php to read real quotes from published authors. 